\title{
ИССЛЕДОВАНИЕ СВОЙСТВ ФАРШЕВЫХ СИСТЕМ ИЗ ГОВЯЖЬЕЙ ПЕЧЕНИ С ДОБАВЛЕНИЕМ КОНОПЛЯНОЙ МУКИ
}

\author{
Т.А. Стопорева, М.А. Вайтанис, С.В. Новоселов
}

\begin{abstract}
Одной из важнейших задач, стоящих перед обществом, является удовлетворение потребностей населения в высококачественных продуктах питания. Массовое питание нуждается в расиирении ассортимента блюд, обладающих повышенной пищевой и биологической ценностью, высоким качеством и экономически выгодным технологическим процессом приготовления. Мясные продукты являются основными в каждодневном рационе человека, так как могут удовлетворять суточную потребность взрослого человека в необходимых питательных веществах. Наиболее ченным из мясного сырья является говяжья печень, содержащая большое количество легкоусвояемого железа, заменимых и незаменимых аминокислот, витаминов, эссенциальных фоссфолипидов. Внесение добавок в мясопродукты получило широкое распространение в настоящее время. Особенно примечательно использование добавок со структурорегулирующими свойствами. Использование таких добавок позволяет влиять на реологические свойства фраршевых систем и приводить к значительному сокращению потерь влаги и питательных веществ при тепловой обработке. Учитывая практический интерес использования добавок в изделиях из рубленного мяса, поставлена цель работы - разработка научно-обоснованной рецептуры и технологии производства изделий из рубленной говяжьей печени с наполнителем в виде конопляной муки и добавлением эмульгированного конопляного масла. Конопляная мука содержит грубые пищевые волокна и пектин оказывающие комплексное оздоравливающее действие на организм человека. По сравнению с другими известными маслами конопляное масло содержит максимальное количество ненасыщенных жирных кислот и витамин $E$.
\end{abstract}

Ключевые слова: говяжья печень, фраршевые системы, пищевая ценность, конопляная мука, добавки, белок, органолептическая оценка, функционально-технологические свойства.

Фаршевая система из говяжьей печени для производства фрормованных кулинарных изделий не используется, так как она крайне нестабильная, растекается и не держит форму. Внесение растительного сырья в виде конопляной муки положительно повлияет на реологические показатели фрарша из говяжьей печени и повысит пищевую и биологическую ценность готовых изделий, так как основным источником белка в рационе человека остаются мясные продукты. [1, 11, 14].

Для проведения исследований была взята рецептура оладий из говяжьей печени из сборника рецептур [5]. Сливочное масло по данной рецептуре было заменено количественно на эмульсию из конопляного масла. Для определения оптимального количества внесения конопляной муки был проведен ряд исследований. Были изготовлены образцы модельных фраршей с различным содержанием конопляной муки к количеству говяжьей печени: $5 \%, 10 \%, 15 \%, 20 \%, 25 \%$ и контрольный образец без добавления муки. Изначально была проведена органолептическая оценка модельных фаршей по ГОСТ Р 553652012 [2], которая представлена в таблице 1.
В результате проведенной оценки можно отметить, что консистенция мясного фарша при внесении от $10 \%$ до $15 \%$ муки становится вязкой, однородной. Дальнейшее внесение муки в количестве от $20 \%$ до $25 \%$ приводит к ухудшению таких показателей как, внешний вид, консистенция и запах. По органолептическим показателям оптимальным является внесение $15 \%$ муки, при отсаживании на лист полусрабрикаты удерживают форму и не растекаются.

Далее были проведены исследования по определению основных фрункционально-технологических свойств фаршевой системы, таких как влагоудерживающая, жироудерживающая, эмульгирующая способности, стабильность эмульсии и $\mathrm{pH}$.

Из функционально-технологических показателей первоначально была определена влагосвязывающая способность, которая выражается содержанием слабосвязанной и прочносвязанной влаги. Стабильность структуры фарша в большинстве случаев зависит от прочности связи воды с фаршевыми частицами. 
Таблица 1 - Органолептические показатели модельных фраршей с добавлением эмульсии из конопляного масла и различным процентом внесения конопляной муки

\begin{tabular}{|c|c|c|c|c|c|c|}
\hline $\begin{array}{l}\text { Органолептиче- } \\
\text { ские показатели }\end{array}$ & $\begin{array}{c}\text { Контрольный } \\
\text { образец }\end{array}$ & Образец 1 & Образец 2 & Образец 3 & Образец 4 & Образец 5 \\
\hline $\begin{array}{c}\text { Содержание } \\
\text { муки, \% }\end{array}$ & 0 & 5 & 10 & 15 & 20 & 25 \\
\hline Внешний вид & \multicolumn{6}{|c|}{$\begin{array}{l}\text { Однородная, хорошо перемешанная масса без кровеносных сгустков, пленок и остат- } \\
\text { ков желчных протоков. При последующем внесении муки отмечаются видимые вкрап- } \\
\text { ления конопляной муки }\end{array}$} \\
\hline Консистенция & \multicolumn{3}{|c|}{ Жидкая } & Вязкая & \multicolumn{2}{|c|}{ Густая } \\
\hline $\begin{array}{l}\text { Степень } \\
\text { измельчения }\end{array}$ & \multicolumn{6}{|c|}{ Не более 3,0 мм } \\
\hline Цвет & $\begin{array}{l}\text { Красно-ко- } \\
\text { ричневый }\end{array}$ & \multicolumn{3}{|c|}{$\begin{array}{l}\text { При добавлении муки цвет становится } \\
\text { темнее, видны темно-зеленые вкрап- } \\
\text { ления частиц муки }\end{array}$} & \multicolumn{2}{|c|}{$\begin{array}{l}\text { Фарш приобретает более } \\
\text { выраженный темно-зеле- } \\
\text { ный оттенок муки }\end{array}$} \\
\hline Запах & $\begin{array}{l}\text { Запах свой- } \\
\text { ственный пе- } \\
\text { чени }\end{array}$ & \multicolumn{3}{|c|}{$\begin{array}{l}\text { Отмечается слегка уловимый расти- } \\
\text { тельный запах конопляной муки }\end{array}$} & \multicolumn{2}{|c|}{$\begin{array}{l}\text { Более выраженный запах } \\
\text { конопляной муки }\end{array}$} \\
\hline
\end{tabular}

Влажностный состав фраршевой системы определяется следующей схемой:

-прочносвязанная влага $\rightarrow$ адсорбционная влага;

- слабосвязанная полезная влага $\rightarrow$ для оптимальной консистенции;

- слабосвязанная избыточная влага $\rightarrow$ отделяемая влага при тепловой обработке.

Свойства фраршевой системы зависят от отношения слабо- и прочносвязанной влаги. Возрастание доли слабосвязанной влаги при- водит к возрастанию ширины прослоек дисперсной среды, в связи с этим происходит ослабление взаимодействия частиц дисперсной фазы. Часть слабосвязанной влаги становится избыточной, что приводит к ее выделению при тепловой обработке $[3,4,12]$. На рисунке 1 представлен график зависимости содержания слабосвязанной и прочносвязанной влаги от количества внесения конопляной муки.

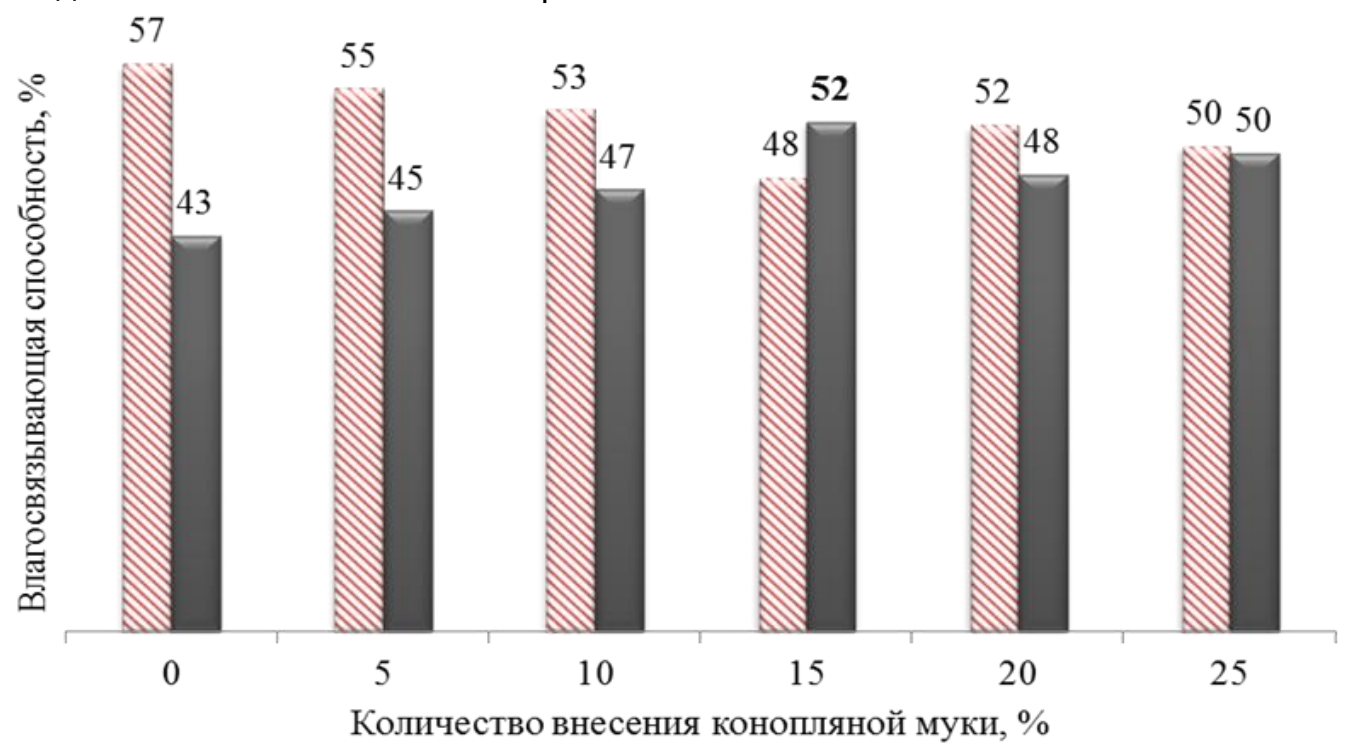

$\triangle$ Содержание слабосвязанной влаги, $\%$ Содержание прочносвязанной влаги, \%

Рисунок 1 - Зависимость влагосвязывающей способности модельных фаршей от процента внесения конопляной муки 


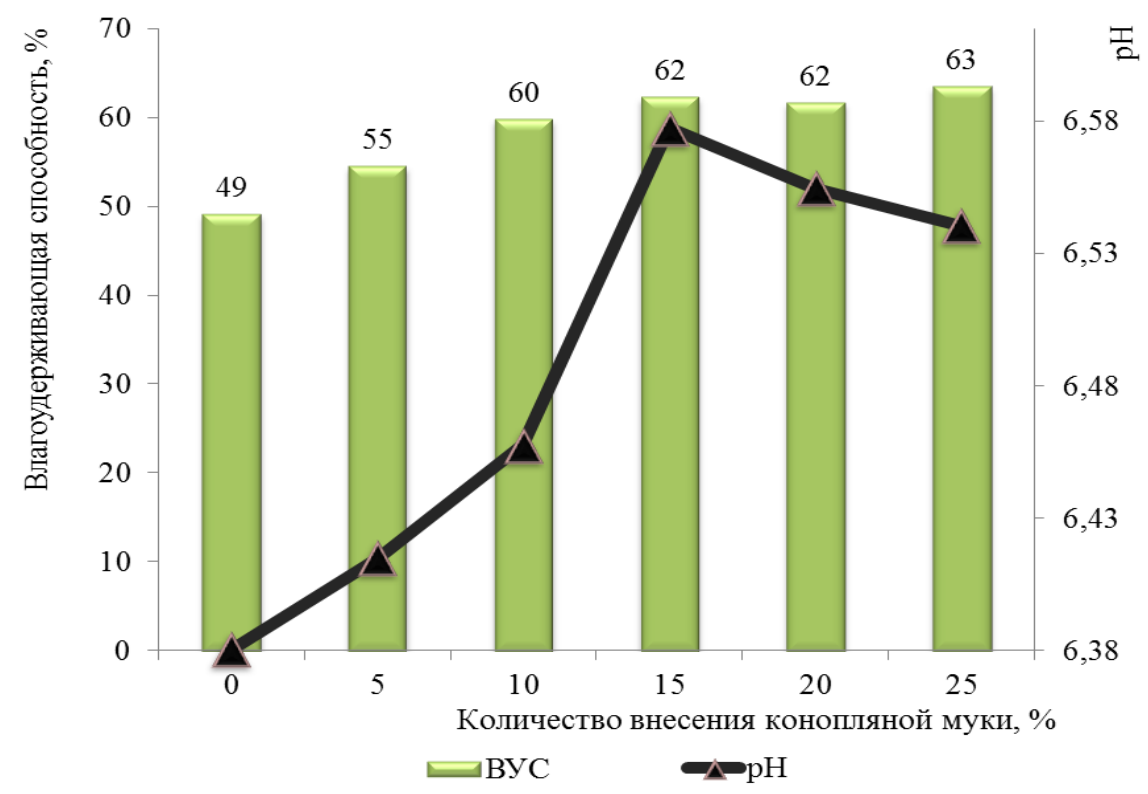

Рисунок 2 - Зависимость влагоудерживающей способности и рН модельных фраршей от количества внесения конопляной муки

Как видно из рисунка 1 содержание слабосвязанной влаги в фарше из говяжьей печени в контрольном образце максимальное. При внесении муки заметно уменьшение количества слабосвязанной влаги и при $15 \%$ наблюдается оптимальное соотношение слабосвязанной и прочносвязанной влаги.

Влагоудерживающая способность является важным показателем для фраршевых систем. Она определяется способностью удерживать в материале влагу. Удержание воды в фрарше имеет большое значение для получения большего выхода, сочности и хорошей консистенции фрарша. Известно, что влагоудерживающая способность - это разница между содержанием влаги в фрарше и количеством отделившейся влаги в процессе термической обработки $[7,8]$. На влагосвязывающую способность могут влиять различные фракторы такие как: содержание соли, степень измельчения фрарша или внесение растительного сырья, обладающего большей способность связывать свободную воду.

На рисунке 2 представлена зависимость влагоудерживающей способности фрарша и $\mathrm{pH}$ из говяжьей печени от количества внесения конопляной муки. Так показано, что стабилизация влагоудерживающей способности наблюдается при внесении в фрарш $15 \%$ конопляной муки. При этом наблюдается возрастание показателя $\mathrm{pH}$.

Жироудерживающая способность связана с адсорбцией жира за счет гидрофробных ради- калов аминокислот. Высокая жироудерживающая способность фраршей обеспечивает нежную и однородную текстуру готовых изделий, исключает выделение жира при тепловой обработке, тем самым уменьшая потери при приготовлении [10]. На рисунке 3 представлен график зависимости жироудерживающей способности модельных фраршей от процента внесения конопляной муки.

Фарш из говяжьей печени с внесением 15 \% конопляной муки обладает высокой жироудерживающей способностью из-за большого содержания в ней белка. Известно, что жироудерживающая способность фаршей находится в тесной взаимосвязи от содержания белка в продукте.

Эмульсия может быть стойкой только при наличии веществ-эмульгаторов, которые, адсорбируясь на поверхности капель жира, препятствуют их слипанию. В мясных системах такими эмульгаторами с выявленной поверхностной активностью являются природные составные части жиров - лецитин, холестерин, моноглицериды, а также солерастворимые белки мышечной ткани.

Взаимодействие жир-белок-вода осуществляется благодаря наличию большого количества гидрофильных и гидрофобных групп в белках. Гидрофобные группы образуют на внешней поверхности капелек жира прочный адсорбционный слой, который играет роль барьера, препятствующего коалесценции жира [6, 9]. 


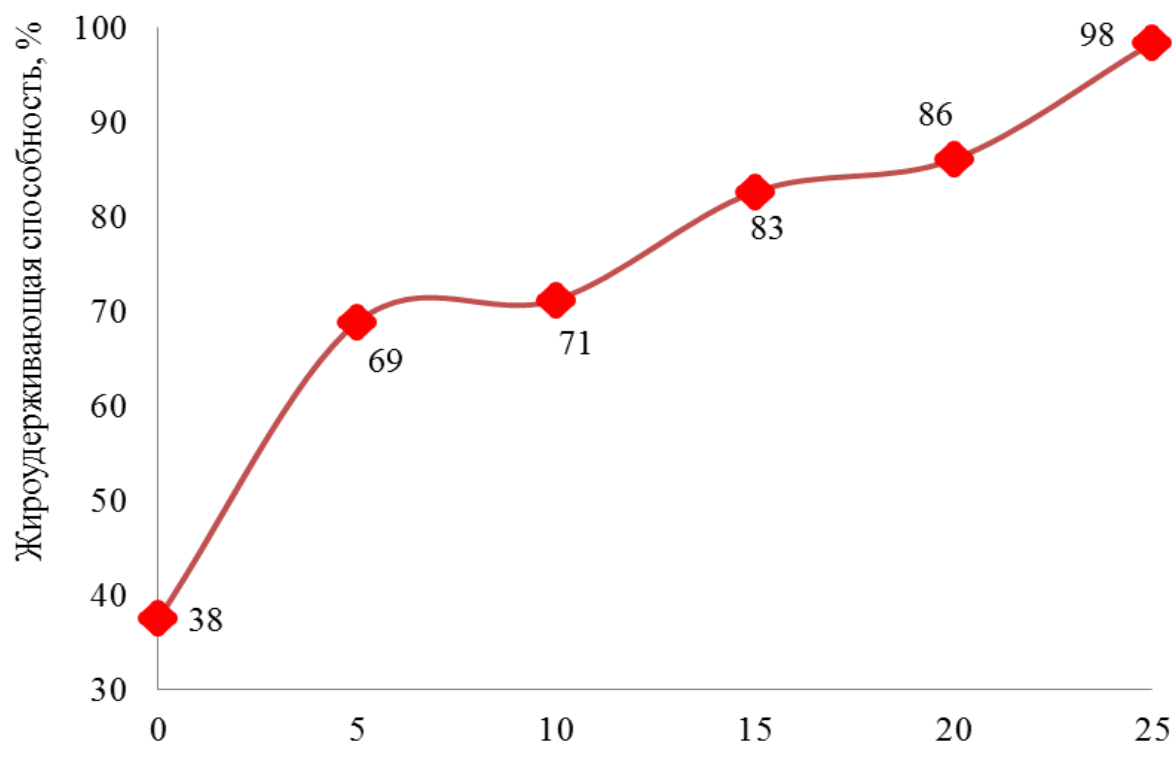

Количество внесения конопляной муки, \%

Рисунок 3 - Зависимость жироудерживающей способности от количества внесения конопляной муки

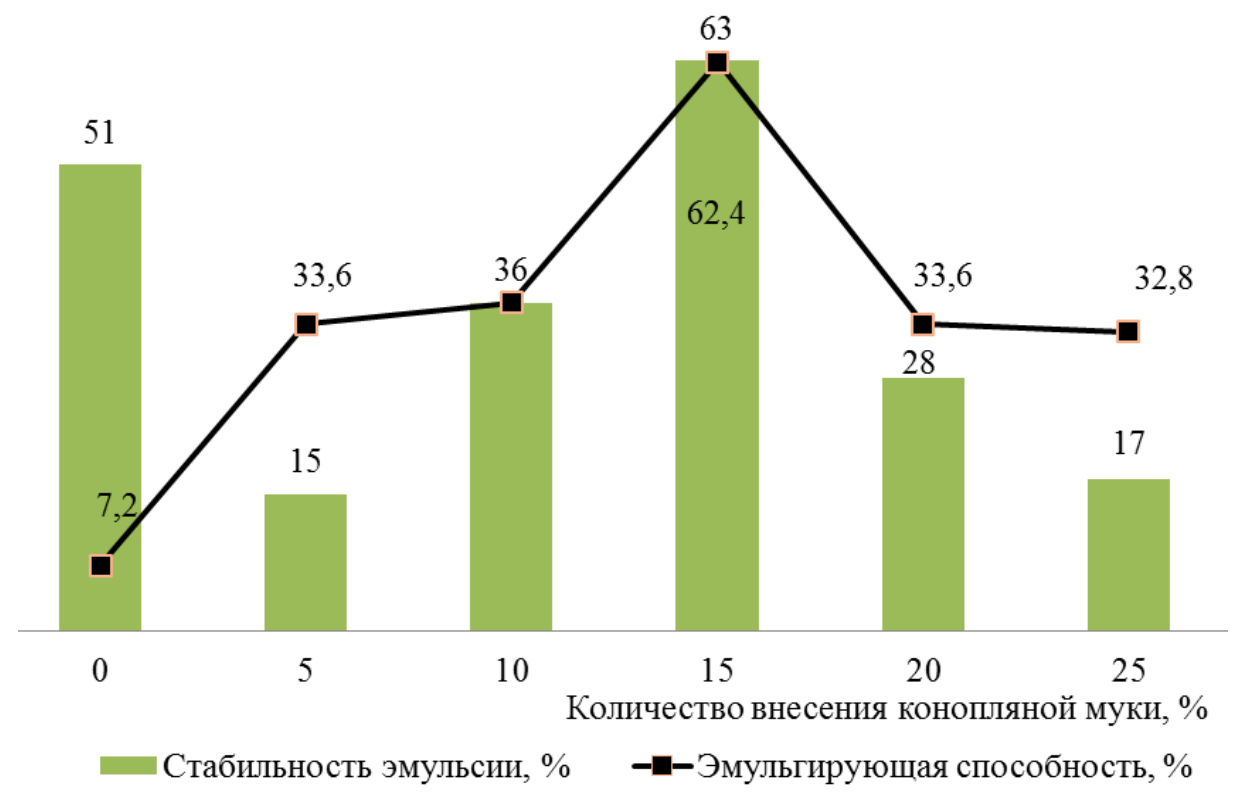

Рисунок 4 - Зависимость стабильности эмульсии и эмульгирующей способности модельных фраршей от доли внесения конопляной муки

Стабильность эмульсии является важным показателем для фаршевых систем, так как от этого зависит стабильность всей фраршевой системы.

Пленки белков являются белковыми гелями и эмульгаторами. Стабильность эмульсии определяет и механические и эластические свойства модельных фаршей. Как видно из рисунка 4 стабильность эмульсии тесно связана с внесением в фраршевую систему конопляной муки, максимальный показатель стабильности эмульсий наблюдается при $15 \%$ внесения муки.

Эмульгирующая способность фарша показывает, насколько правильно приготовлена мясная эмульсия жир в воде и как выполняется взаимодействие - белок: жир: вода. Высокая эмульгирующая способность, позволяет 


\section{ИССЛЕДОВАНИЕ СВОЙСТВ ФАРШЕВЫХ СИСТЕМ ИЗ ГОВЯЖЬЕЙ ПЕЧЕНИ С ДОБАВЛЕНИЕМ КОНОПЛЯНОЙ МУКИ}

получить продукт, который держит форму. Высокая эмульгирующая способность у модельного фарша с $15 \%$ добавлением конопляной муки объясняется большим содержанием в ней белка, что позволяет получать устойчивые фаршевые системы (рис. 4).

Как видно из проведенных исследований, внесение $15 \%$ конопляной муки в фраршевую систему из говяжьей печени является оптимальным для улучшения органолептических и функционально-технологических свойств. Для закрепления результата была проведена дегустационная оценка готовых оладий без внесения муки и с $15 \%$ добавлением конопляной муки. Результаты дегустационной оценки представлены на рисунке 5.

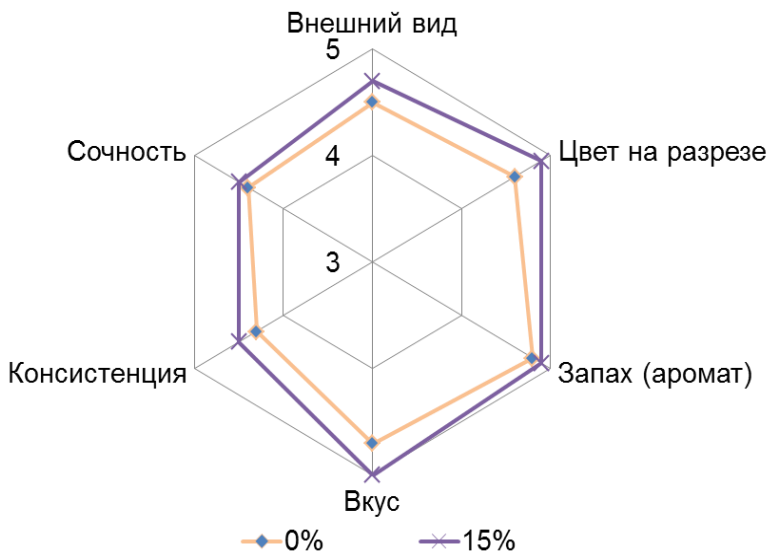

Рисунок 5 - Профилограмма дегустационной оценки оладий из говяжьей печени с

$15 \%$ внесением конопляной муки и контрольный образец, без добавления муки

Дегустационную оценку оладий из печени с различным добавлением конопляной муки проводили с помощью метода экспертных оценок [13]. Метод экспертных оценок позволяет определить способ качественного совершенствования продукции путем обобщения мнения экспертов. Степень согласованности экспертов оценивали по величине коэфффициента конкордации Кендалла. В результате получили, что коэффицциент конкордации составил - 0,91, что свидетельствует о достаточно высокой согласованности мнений экспертов.

Таким образом, в результате проведенных исследований установлено, что внесение $15 \%$ конопляной муки в фарш из говяжьей печени увеличивает влагосвязывающую и влагоудерживающую способность, положительно влияет на жироудерживающую, эмульгирующую способности и стабильность эмульсии. Это также подтверждается проведенной дегустационной оценкой.
Применение конопляной муки в приготовлении изделий из рубленной говяжьей печени показывает высокие фрункционально-технологические характеристики и позволяет расширить ассортимент мясных изделий из такого не популярного и полезного сырья как говяжья печень.

\section{СПИСОК ЛИТЕРАТУРЫ}

1. Рамазаева, Л.Ф. Влияние добавки из семян нута на органолептические и физико-химические показатели мясорастительных консервов / Л.Ф. Рамазаева, И.Л. Казанцева // Известия ВУЗов. Пищевая технология. - 2010. - № 2-3. - С. 28-30.

2. ГОСТ Р 55365-2012 «Фарш мясной. Технические условия» [Электронный ресурс]/ Официальный сайт «Техэксперт»/ http://docs.cntd.ru/ (дата обращения 15.04.2018 г)

3. Осипова, Л.Д. Разработка кулинарной продукции из рубленного мяса повышенной водо- и жироудерживающей способности: Дис. ... канд. техн. наук: 05.18.15. - Орел, 2004. - 220 с.

4. Стопорева, Т.А. Оценка качества нового биологически ценного продукта на основе фаршевой системы из говяжьей печени [Текст] / Т.А. Стопорева, М.А. Вайтанис // От биопродуктов к биоэкономике: материалы II межрегиональной научнопрактической конференции (с международным участием). Правительство Алтайского края. - Барнаул: Изд-во АлтГТУ, 2018. - С. 221-224.

5. Новейший сборник рецептур блюд и кулинарных изделий для предприятий общественного питания. - М.: ООО «Дом Славянской кни-ги», 2017. $-576 \mathrm{c}$.

6. Жаринов, А.И. Основы современных технологий переработки мяса. Часть 2. Цельномышечные и реструктурированные мясопродукты. - М.: Академия, 1997. - 472 с.

7. Журавская, Н.К. Технохимический контроль производства мяса и мясопродуктов / Н.К. Журавская, Б.Е. Гутник, Н.А. Журавская. - М.: Колос, 2001. $-176 \mathrm{c}$.

8. Антипова, Л. В. Методы исследования мяса и мясных продуктов / И. А. Глотова, И. А. Рогов. - М.: Колос, 2001. - 376 с.

9. Васюкова, А.Т. Технология продукции общественного питания: лабораторный практикум/ А.Т. Васюкова, А.С. Ратушный. - М.: Издательско-торговая корпорация «Дашков и К», 2007. - 108 с.

10. Рогов, И.А. Биотехнология мяса и мясопродуктов. Курс лекций/ Жаринов А.И., Текутьева Л.А., Шепель Т.А. - М.: ДеЛи принт, 2009. - 296 с.

11. Скурихин, И.М. Химический состав российских продуктов питания: Справочник / И.М. Скурихин, В.А. Тутельян. - М.: ДеЛи принт, 2002. - 236 с.

12. Винникова, Л.Г. Технология мяса и мясных продуктов. - Киев: Фирма «ИНКОС», 2006. - 600 с.

13. Мусина, О.Н. Планирование и постановка научного эксперимента: учебно-методическое пособие для магистрантов направления 260800 «Технология продукции и организация общественного питания. - Барнаул: Издательство АлтГТУ, 2014. - 91 с. 
14. Переходова, Е.А. Использование конопляной муки в производстве мясных рубленых полуфабрикатов/ Е.А. Переходова, Н.Л. Наумова, А.А. Лукин// Продукты функционального и специализированного назначения. - 2017. - № 4 (45). - С. 43 - 45.

Новоселов Сергей Владимирович, д.т.н., профрессор, кафредры механики и инноватики ФГБОУ ВО "Алтайский государственный технический университет", 656038, Россия, е. Барнаул, пр-т Ленина 46, e-mail: novoselov sv@mail.ru.
Вайтанис Марина Александровна, к.т.н., доцент кафредры технологии продуктов питания ФГБОУ ВО "Алтайский государственный технический университет", 656038, Россия, г. Барнаул, пр-т Ленина 46, e-mail: gazenauer@yandex.ru.

Стопорева Татьяна Александровна, к.т.н., заведующий отделом аспирантуры и докторантуры ФГБОУ ВО "Алтайский государственный технический университет", 656038, Россия, г. Барнаул, пр-т Ленина 46, e-mail: aspirantura agtu@mail.ru, тел.: (3852) 29-09-24 